\title{
Robust aptamer-polydopamine-functionalized M-PLGA-TPGS nanoparticles for targeted delivery of docetaxel and enhanced cervical cancer therapy
}

This article was published in the following Dove Press journal:

International Journal of Nanomedicine

22 June 2016

Number of times this article has been viewed

\author{
Guojun $\mathrm{Xu}{ }^{1-3, *}$ \\ Xinghua $\mathrm{Yu}^{2, *}$ \\ Jinxie Zhang ${ }^{1,2, *}$ \\ Yingchao Sheng ${ }^{4}$ \\ Gan Liu ${ }^{2}$ \\ Wei Tao ${ }^{1,2}$ \\ Lin $\mathrm{Mei}^{1,2}$
}

'School of Life Sciences, Tsinghua University, Beijing, ${ }^{2}$ Graduate School at Shenzhen, Tsinghua University, Shenzhen, ${ }^{3}$ School of Materials Science and Engineering, Tsinghua University, Beijing, ${ }^{4}$ Department of Orthopedic Surgery, Changshu Hospital of TCM, Changshu, People's Republic of China

*These authors contributed equally to this work
Correspondence: Wei Tao

School of Life Sciences, Tsinghua

University, 30 Shuangqing Road, Beijing

100084, People's Republic of China

$\mathrm{Tel} / \mathrm{fax}+86010627734 \mathrm{II}$

Email taowei@tsinghua.edu.cn
Abstract: One limitation of current biodegradable polymeric nanoparticles (NPs) is the contradiction between functional modification and maintaining formerly excellent bioproperties with simple procedures. Here, we reported a robust aptamer-polydopamine-functionalized mannitol-functionalized poly(lactide-co-glycolide) (M-PLGA)-D- $\alpha$-tocopheryl polyethylene glycol 1000 succinate (TPGS) nanoformulation (Apt-pD-NPs) for the delivery of docetaxel (DTX) with enhanced cervical cancer therapy effects. The novel DTX-loaded Apt-pD-NPs possess satisfactory advantages: 1) increased drug loading content and encapsulation efficiency induced by star-shaped copolymer M-PLGA-TPGS; 2) significant active targeting effect caused by conjugated AS1411 aptamers; and 3) excellent long-term compatibility by incorporation of TPGS. Therefore, with simple preparation procedures and excellent bioproperties, the new functionalized Apt-pD-NPs could maximally increase the local effective drug concentration on tumor sites, achieving enhanced treatment effectiveness and minimizing side effects. In a word, the robust DTX-loaded Apt-pD-NPs could be used as potential nanotherapeutics for cervical cancer treatment, and the aptamer-polydopamine modification strategy could be a promising method for active targeting of cancer therapy with simple procedures.

Keywords: dopamine, AS1411 aptamer, active targeting, polymeric NPs, enhanced cervical chemotherapy

\section{Introduction}

Cervical cancer is one of the most common malignant tumors and serious health problems, especially in developing countries. Both the morbidity and the mortality of cervical cancer have substantially increased in recent years. However, chemotherapy, which is one of the most used clinical treatments for cervical cancer nowadays, is nonspecific, and huge disadvantages such as serious side effects due to the lack of effective carriers still exist. ${ }^{1-3}$ As an efficient solution, polymeric nanoparticles (NPs) have been employed as highly promising carriers for anticancer drugs, functioning as sustained, controlled, and targeted drug delivery systems to improve the therapeutic effects for cervical cancer and to reduce the side effects on normal organs. ${ }^{4-8}$ In order to transport the NPs to tumor cells in vivo, a relatively long circulating half-life and sufficient target interaction are the two essential requirements that could be achieved through surface modification. ${ }^{9}$

Aptamers, which are single-stranded RNA or DNA ligands, are oligonucleotides or peptide molecules that bind a wide variety of biological targets on cancer cells with high affinity and specificity. ${ }^{10-12}$ Aptamers can be used for both basic research and clinical purposes as macromolecular drugs. Aptamers can also be combined with ribozymes 
to self-cleave in the presence of their target molecules. These compound molecules have additional research, industrial, and clinical applications. Owing to higher in vivo stability ${ }^{13}$ and good targeting moieties, aptamers are widely used in therapeutic applications. ${ }^{14}$ AS1411 is one of the frequently used DNA aptamers that can inhibit the viabilities of various cancer cells, such as prostate cancer cells (DU145), breast cancer cells (MCF-7), ${ }^{15}$ and cervical cancer cells (HeLa). Due to its superior performance on enhanced therapeutic effects and targeting efficacy, it can be used as an efficient targeting ligand for surface modification of NPs in cervical cancer treatment. However, for NPs prepared using prefunctionalized polymers, the synthesis of polymeraptamer conjugates can be inefficient, lengthy with high cost, at a risk of altering the chemical properties, and compromising the ability of the polymer to encapsulate drugs. ${ }^{16}$

To successfully address these issues, we adopt a novel, simple, and versatile modification technique based on dopamine polymerization. Modification of the NP surface with hydrophilic, electrically neutral polymers such as polydopamine $(\mathrm{pD})$ can achieve a crucial effect to incorporate functionalized ligands (eg, peptides, nucleic acids, and small molecules). Dopamine, which was a kind of traditional neurotransmitter inspired by the chemical constituents of adhesive proteins in mussels, ${ }^{17}$ has been reported to be used in modification of the surface of materials. ${ }^{18}$ Park et al ${ }^{19}$ also demonstrated that the dopamine polymerization method is a simple and versatile surface modification pathway, applicable to a variety of NP drug carriers irrespective of their chemical reactivity and the types of ligands (eg, small molecules, peptides, and polymers). In brief, dopamine catechol can be oxidized to quinone that reacts with other catechols or quinones to form polydopamine in weak alkaline conditions ( $\sim \mathrm{pH} 8-\mathrm{pH} 8.5$ ), eventually forming a water-insoluble polymer film on the surface of NPs. ${ }^{20}$ After that, ligands possessing nucleophilic functional groups (eg, amine and thiol) can be incorporated into the surface layer via Michael addition or Schiff base reactions. ${ }^{21-23}$

In our previous research, ${ }^{24}$ a star-shaped mannitolfunctionalized poly(lactide-co-glycolide) (M-PLGA)-D$\alpha$-tocopheryl polyethylene glycol 1000 succinate (TPGS) copolymer was successfully synthesized and characterized, and the docetaxel (DTX)-loaded M-PLGA-TPGS NPs have been demonstrated to have many superiorities, for example, increased bioavailability of anticancer drugs (solubility, permeability, and stability), improved drug loading content (LC) and encapsulation efficiency (EE), accelerated drug release, and good in vitro antitumor efficiency. Hence, we continued our further research on M-PLGA-TPGS NPs for cervical cancer therapy and inferred that aptamers could be conjugated to pD-modified M-PLGA-TPGS NPs. The new and improved functionalized NPs were characterized, and the antitumor effects were investigated both in vitro and in vivo.

\section{Materials and methods \\ Materials}

Mannitol $\left(\mathrm{C}_{6} \mathrm{H}_{14} \mathrm{O}_{6}\right)$, (TPGS $\left(\mathrm{C}_{33} \mathrm{O}_{5} \mathrm{H}_{54}\left(\mathrm{CH}_{2} \mathrm{CH}_{2} \mathrm{O}\right)_{23}\right)$ ), coumarin-6(C6), D,L-lactide (3,6-dimethyl-1,4-dioxane-2,5-dione, $\left.\mathrm{C}_{6} \mathrm{H}_{8} \mathrm{O}_{4}\right), 2-(3,4-$ dihydroxyphenyl) ethylamine (dopamine) hydrochloride, propidium iodide, and 3-(4,5-dimethylthiazol2-yl)-2,5-diphenyltetrazolium bromide (MTT) were purchased from Sigma-Aldrich Co. (St Louis, MO, USA). PLGA (LA:GA $=75: 25, \mathrm{Mn} \approx 25,000$ ) was purchased from Jinan Daigang Biomaterial Co. Ltd (Jinan, People's Republic of China). DTX was provided by Beijing InnoChem Science \& Technology Co., Ltd (Beijing, People's Republic of China). Commercial Taxotere $^{\circledR}$ (purity: 99.9\%) was bought from Shanghai Jinhe Bio-Technology Co., Ltd (Shanghai, People's Republic of China). All other agents used were of the highest commercial grade available. Human cervix carcinoma cell line HeLa was purchased from American Type Culture Collection (Manassas, VA, USA). The Administrative Committee on Animal and Cell Research in Tsinghua University approved the protocols for cellular assays.

\section{Synthesis of DTX-loaded Apt-pD-NPs Preparation of DTX-loaded M-PLGA-TPGS NPs}

A modified nanoprecipitation method with an acetone/water system was used to prepare the DTX-loaded M-PLGA-TPGS NPs (DTX-loaded NPs). ${ }^{25,26}$ Briefly, $20 \mathrm{mg}$ DTX and $200 \mathrm{mg}$ M-PLGA- $b$-TPGS copolymers powder were dissolved in $16 \mathrm{~mL}$ of acetone. The blend solution was titrated into $200 \mathrm{~mL}$ of $0.03 \%$ (w/v) TPGS aqueous solution under stirring. After stirring overnight $(800 \mathrm{rpm})$ at room temperature to remove acetone, the DTX-loaded NPs were centrifuged at $20,000 \mathrm{rpm}\left(4^{\circ} \mathrm{C}\right)$ for 20 minutes and washed three times in $20 \mathrm{~mL}$ of deionized water to remove unencapsulated drug and TPGS emulsifier. At last, we selected precalculated amount of the precipitated DTX-loaded NPs for pD coating, while the left DTX-loaded NPs were dispersed in deionized water and lyophilized for 2 days for further use.

\section{Prime coating with $\mathrm{pD}$}

The DTX-loaded and pD-coated NPs (DTX-loaded pD-NPs) were synthesized by incubating DTX-loaded NPs in $0.1 \mathrm{mg} / \mathrm{mL}$ dopamine hydrochloride/Tris buffer solution ( $\mathrm{pH} 8.5$, dopamine hydrochloride dissolved in a $10 \mathrm{mM}$ 
Tris buffer) under stirring at room temperature. After magnetic stirring for 6 hours, the suspensions turned dark when dopamine hydrochloride was added, indicating that dopamine was successfully polymerized. The obtained DTX-loaded pD-NPs were centrifuged and lyophilized for aptamer conjugation.

\section{Conjugation of aptamers to pD-coated NPs}

The AS1411 aptamers (5'-GGT GGT GGT GGT TGT GGT GGT GGT GGT TTT TTT TTT-thiol-3'), whose sequence contains ten extra $\mathrm{T}$ bases at the 3-terminus, were connected to the surface of DTX-loaded pD-NPs via the Michael addition reaction. ${ }^{19}$ In brief, the DTX-loaded pD-NPs were resuspended in Tris buffer ( $\mathrm{pH}$ 8.0) containing aptamers. The final concentration of DTX-loaded pD-NPs and aptamers was $1 \mathrm{mg} / \mathrm{mL}$ and $0.5 \mathrm{mg} / \mathrm{mL}$, respectively. After magnetic stirring for 2 hours at room temperature, the resulting NPs (designated as DTX-loaded Apt-pD-NPs) were centrifuged, washed three times with deionized water, and lyophilized for 2 days.

All the fluorescent (C6- or IR-780-loaded) NPs were fabricated in a similar manner at each of the three steps described earlier. All the lyophilized NPs were redispersed in phosphatebuffered saline (PBS) before use.

\section{Characterization of functionalized NPs} Particle size, zeta potential, and morphology

The size of DTX-loaded NPs, DTX-loaded pD-NPs, and DTX-loaded Apt-pD-NPs was analyzed using Malvern Mastersizer 2000 (Zetasizer Nano ZS90; Malvern Instruments, Malvern, UK). ${ }^{27}$ The NPs were resuspended in deionized water before experiments. These data were obtained by averaging the values obtained at three time points. The surface morphology of the NPs was measured by a field emission scanning electron microscopy (FESEM; JEOL JSM-6700F, Tokyo, Japan) and a transmission electron microscopy (TEM; Tecnai G² F30; FEI Company, Hillsboro, OR, USA).

\section{Fourier transform infrared spectroscopy analysis}

The Fourier transform infrared (FT-IR) spectroscopy analysis of drug-free NPs, drug-free pD-NPs, and drug-free Apt-pDNPs was recorded by FT-IR spectrophotometer (Thermo Nicolet, Madison, WI, USA) using $\mathrm{KBr}$.

\section{X-ray photoelectron spectroscopy}

The X-ray photoelectron spectroscopy (XPS) of the DTX-loaded NPs, DTX-loaded pD-NPs, and DTX-loaded Apt-pD-NPs was obtained by a Kratos Axis Ultra DLD spectrometer (Kratos Analytical Ltd, Manchester, UK) with monochromatic Al K $\alpha$ radiation $(h v=1,486.58 \mathrm{eV})$. Survey and high-resolution spectra were collected at a fixed analyzer pass energy of $160 \mathrm{eV}$ and $20 \mathrm{eV}$, respectively. Binding energy values were referenced to the Fermi edge, and charge correction was performed setting the $\mathrm{C} 1 \mathrm{~s}$ peak at $284.80 \mathrm{eV}$.

\section{Drug LC and EE}

The solution, which was prepared using $5 \mathrm{mg}$ NPs dissolved in $1 \mathrm{~mL}$ of dichloromethane under vigorous vortexing, was transferred to $5 \mathrm{~mL}$ of mobile phase consisting of acetonitrile and deionized water $(50: 50, \mathrm{v} / \mathrm{v})$. The LC and EE of the modified NPs were determined by high-performance liquid chromatography (HPLC; LC 1200; Agilent Technologies, Santa Clara, CA, USA), and to obtain a clear solution for HPLC, a nitrogen stream was introduced for $\sim 15$ minutes to evaporate dichloromethane. A reverse-phase C18 column (150×4.6 mm, $5 \mu \mathrm{m}, \mathrm{C} 18$; Agilent Technologies) was used at $35^{\circ} \mathrm{C}$. The flow rate of mobile phase was set at $1.0 \mathrm{~mL} / \mathrm{min}$. The column effluent was detected at $227 \mathrm{~nm}$ using a UV/VIS detector. Measurements were carried out three times for each batch. The LC and EE of modified NPs were calculated by the following equations, respectively.

$$
\text { LC }(\%)=\frac{\text { Weight of DTX in NPs }}{\text { Weight of NPs }} \times 100 \%
$$

$$
\mathrm{EE}(\%)=\frac{\text { Weight of DTX in NPs }}{\text { Weight of the feeding DTX }} \times 100 \%
$$

\section{In vitro drug release profiles}

Before the testing of in vitro DTX release profiles, $5 \mathrm{mg}$ of the lyophilized NPs was put in a centrifuge tube and dispersed in $10 \mathrm{~mL}$ of PBS ( $\mathrm{pH} 7.4$, containing $0.1 \% \mathrm{w} / \mathrm{v}$ Tween 80). Tween 80 was added to avoid the binding of DTX to the tube wall and to increase the solubility of DTX in the buffer. The supernatant was then transferred into a dialysis membrane bag (molecular weight cut off $[\mathrm{MWCO}]=3,500$; Shanghai Sangon, People's Republic of China) that was immersed in $10 \mathrm{~mL}$ of fresh PBS release medium in a centrifuge tube. At designated time intervals, the tube was transferred into an orbital water bath and shaken at $200 \mathrm{rpm}$ at $37^{\circ} \mathrm{C}$. The cumulative release buffer outside the dialysis bag was plotted to HPLC analysis.

\section{Endocytosis of fluorescent NPs}

HeLa cells were cultured in a chambered cover glass system in Dulbecco's Modified Eagle's Medium (DMEM) supplemented with $10 \%$ fetal bovine serum, $100 \mathrm{U} / \mathrm{mL}$ penicillin, and $100 \mathrm{mg} / \mathrm{mL}$ streptomycin in $5 \% \mathrm{CO}_{2}$ at $37^{\circ} \mathrm{C}$. The culture was kept in 95\% air humidified atmosphere. The cells were incubated with $250 \mu \mathrm{g} / \mathrm{mL}$ C6-loaded NPs (or pD-NPs or 
Apt-pD-NPs) for 2 hours, washed with cold PBS three times, and fixed with cold methanol for 20 minutes. After that, the nuclei were counterstained with propidium iodide for 30 minutes and washed twice with PBS. In order to visualize the cells, the chambers were mounted onto the confocal laser scanning microscope (FV-1000, Olympus FluoView ${ }^{\text {TM, }}$ Tokyo, Japan) with the following channels: a blue channel excited at $340 \mathrm{~nm}$ and a green channel excited at $485 \mathrm{~nm}$.

For quantitative analysis, HeLa cells were plated in 96-well black plates and incubated overnight with their initial density: $1 \times 10^{4}$ cells/well. The cells were then equilibrated with Hank's buffered salt solution for 1 hour at $37^{\circ} \mathrm{C}$, and C6-loaded NPs (or pD-NPs or Apt-pD-NPs) were added at concentrations $100 \mu \mathrm{g} / \mathrm{mL}, 250 \mu \mathrm{g} / \mathrm{mL}$, and $500 \mu \mathrm{g} / \mathrm{mL}$. After incubation for 2 hours, the medium was removed and the wells were washed three times with $50 \mu \mathrm{L}$ cold PBS. Finally, $50 \mu \mathrm{L}$ of $0.5 \%$ Triton $\mathrm{X}-100$ in $0.2 \mathrm{~N}$ sodium hydroxide was put into each sample well to lyse the cells.

\section{Cell viability evaluation}

To evaluate the in vitro antitumor cytotoxicity of the DTXloaded NPs, DTX-loaded pD-NPs, and DTX-loaded Apt-pDNPs, HeLa cells were seeded at a density of 5,000 cells/well in 96-well plates and incubated overnight. Afterward, the cells were incubated with drug-free NPs, drug-free pD-NPs, drugfree Apt-pD-NPs, commercial Taxotere, DTX-loaded NPs, DTX-loaded pD-NPs, or DTX-loaded Apt-pD-NPs suspension at $0.25 \mu \mathrm{g} / \mathrm{mL}, 2.5 \mu \mathrm{g} / \mathrm{mL}, 12.5 \mu \mathrm{g} / \mathrm{mL}$, and $25 \mu \mathrm{g} / \mathrm{mL}$ equivalent DTX concentrations for 24 hours and 48 hours. The formulations were changed with MTT-contained DMEM $(5 \mathrm{mg} / \mathrm{mL})$, and the cells were incubated for an additional 4 hours at a determined time. Then, dimethyl sulfoxide was added to dissolve the formazan crystals (dark, 2 hours), and MTT was removed at $37^{\circ} \mathrm{C}$. A microplate reader (BioRad Model 680, Bio-Rad Laboratories Inc., Hercules, CA, USA) was used to measure the absorbance at $570 \mathrm{~nm}$. Untreated cells served as $100 \%$ viability and cells incubated with MTT-free medium were taken as blank to calibrate the spectrophotometer to zero absorbance. The drug concentration, at which the growth of $50 \%$ cells was inhibited (defined as $\mathrm{IC}_{50}$ ), was detected by curve fitting of the cell viability data in comparison with that of the control groups.

\section{Xenograft tumor model and in vivo antitumor effects}

The Institute of Laboratory Animal Sciences, Chinese Academy of Medical Science, provided the female severe combined immunodeficient (SCID) mice aged 4-5 weeks old. The Administrative Committee on Animal Research in Tsinghua
University approved the protocols for animal assays and all experimental procedures were carried out according to the Animal Care guidelines. About $100 \mu \mathrm{L}$ of HeLa cells in PBS were implanted subcutaneously into the backs of mice (15-20 g) at a dosage of $2 \times 10^{6}$ cells per mouse. After that, we observed the tumor growth in each mouse at frequent intervals. A Vernier caliper was used to survey the tumor size, and the tumor volume $(V)$ was calculated as $4 \pi / 3 \times($ length $/ 2) \times(\text { width } / 2)^{2}$. Ninety-five percent of the mice injected developed a tumor with an average volume of $\sim 80 \mathrm{~mm}^{3}$ after 10 days. Treatments were started after the tumor size reached $\sim 80 \mathrm{~mm}^{3}$. Two experienced researchers randomly divided the mice into five groups $(n=5)$, which were intravenously injected with saline as a control, DTX-loaded NPs, DTX-loaded pD-NPs, DTX-loaded Apt-pD-NPs, and Taxotere, respectively, at a DTX dose of $10 \mathrm{mg} / \mathrm{kg}$ in $100 \mu \mathrm{L}$ PBS on days $0,4,8,12,16$, and 20 . The body weights and tumor size of each mouse were recorded every other day. The mice were humanely killed after 24 days of treatment. The antitumor efficacy was investigated via tumor growth in this study.

The antitumor efficacy of the DTX-loaded Apt-pD-NPs was also investigated on another batch of SCID mice bearing HeLa tumor xenograft, by measuring their survival time after treatments. After choosing 20 mice with similar body status (ie, age, weight, and $80 \mathrm{~mm}^{3}$ of tumor size), the mice were randomly divided into five groups $(n=5)$ and injected with Taxotere, DTX-loaded NPs, DTX-loaded pD-NPs, and DTXloaded Apt-pD-NPs (DTX dose of $10 \mathrm{mg} / \mathrm{kg}$ ), and saline via tail vein for every 4 days. The survival data were presented as Kaplan-Meier plots and analyzed with a log-rank test.

\section{Statistical methodology}

All tests were carried out at least three times in all experiments unless otherwise stated. The results are expressed as mean $\pm \mathrm{SD}$, and the statistical significance of all the results was determined by the Student's $t$-test. The results were considered to be statistically significant if $P<0.05$.

\section{Results and discussion Fabrication of DTX-loaded Apt-pD-NPs}

The preparation of DTX-loaded Apt-pD-NPs is exhibited in Figure 1. During the polymerization of dopamine, a tight $\mathrm{pD}$ layer surrounded the surface of M-PLGA-TPGS NPs, which were immersed in the dopamine solution. As shown in Figure 1, there were two fatal processes of functionalized DTX-loaded Apt-pD-NPs: in a weak alkaline condition, dopamine was able to undergo oxidative polymerization in the presence of oxygen as an oxidant on the surface of M-PLGA-TPGS (Process I) and conjugation of aptamers to pD-coated NPs (DTX-loaded pD-NPs) with a Michael 

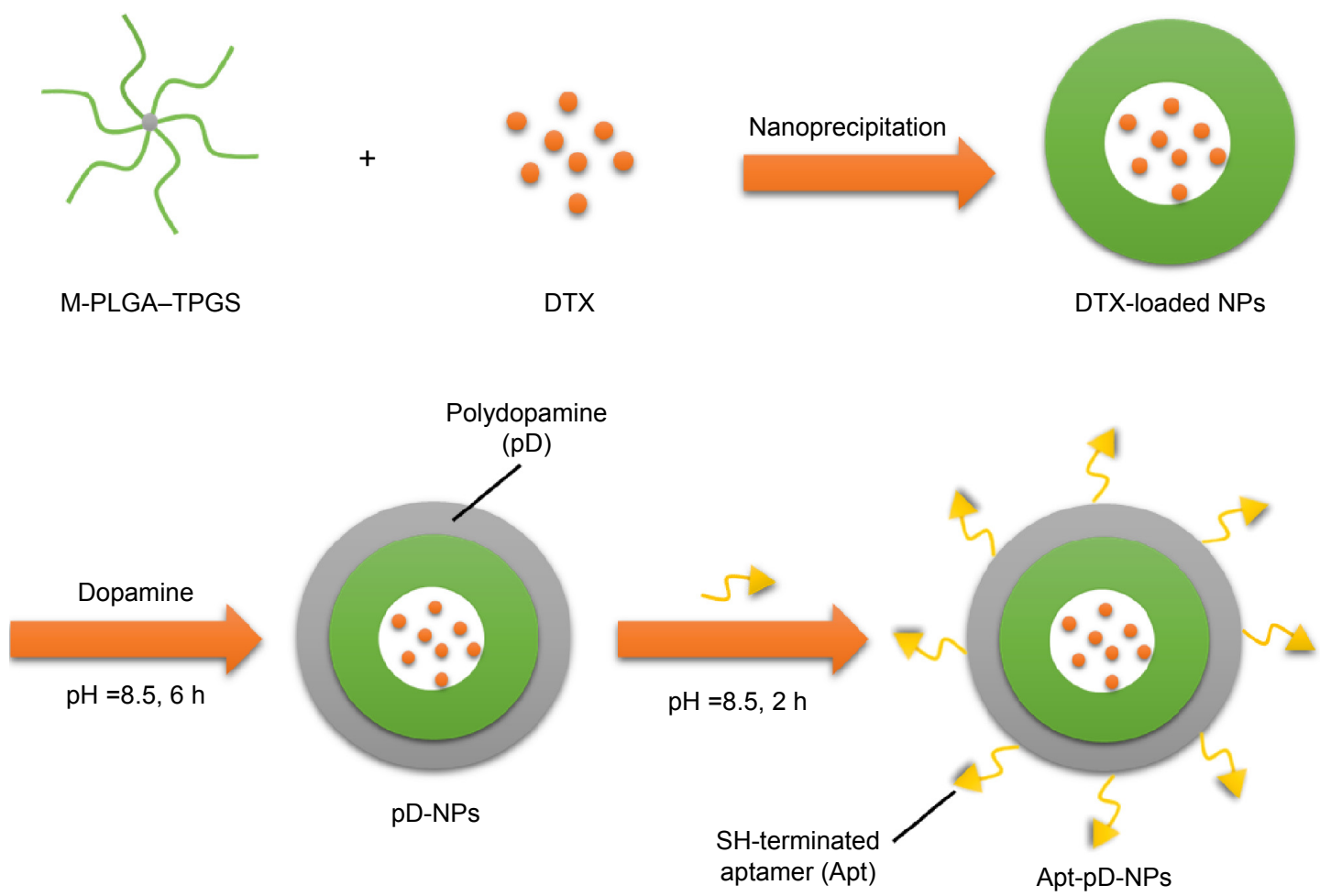

Figure I Schematic representation of the preparation procedure for targeted and DTX-loaded Apt-pD-NPs.

Notes: There were two fatal processes of functionalized DTX-loaded Apt-pD-NPs: oxidative polymerization of dopamine in the presence of oxygen as an oxidant on the surface of M-PLGA-TPGS (Process I) and conjugation of aptamers to PD-coated NPs (DTX-loaded pD-NPs) with a Michael addition reaction (Process II).

Abbreviations: DTX, docetaxel; Apt, aptamer; pD, polydopamine; NPs, nanoparticles; M-PLGA, mannitol-functionalized poly(lactide-co-glycolide); TPGS, D- $\alpha$-tocopheryl polyethylene glycol 1000 succinate; h, hours.

addition reaction (Process II). It turned out that dopamine was successfully polymerized, while the suspensions turned dark with some particulate $\mathrm{pD}$ appearing during the washing steps. Afterward, a 26-mer SH-terminated DNA aptamer (AS1411) was conjugated with the pD-coated NPs, and it was deemed to be targeted therapy for cervical cancer.

\section{Characteristics of DTX-loaded Apt-pD-NPs}

The FT-IR spectroscopy of the drug-free NPs, pD-NPs, and Apt-pD-NPs is exhibited in Figure 2. As for drug-free $\mathrm{NPs}$, the absorption band at $1,750 \mathrm{~cm}^{-1}$ was assigned to the carbonyl band of TPGS and PLGA. ${ }^{28}$ The absorption band at $1,600 \mathrm{~cm}^{-1}$ with aromatic rings stretching vibration of $\mathrm{pD}$ supported the fact that the $\mathrm{pD}$ was coated on the surface of NPs. ${ }^{29}$ In addition, the $1,750 \mathrm{~cm}^{-1}$ band significantly decreased and nearly disappeared. It turned out that both the pD-coating and the aptamers for Apt-pD-NPs were conjugated. XPS was studied to further demonstrate the successful modification of $\mathrm{pD}$ and conjugation of aptamers. As displayed in Figure 3, both pD-NPs and Apt-pD-NPs showed two nitrogen peaks (N 1s) at $\sim 398.8 \mathrm{eV}$ (nonprotonated amine groups) and $\sim 402.1 \mathrm{eV}$ (protonated amine groups) in XPS spectra, but bare NPs did not, verifying the presence of $\mathrm{pD}$ films on the NP surface. In the case of carbon peaks (C 1s), the increased intensity (pD-NPs or Apt-pD-NPs vs bare NPs) at $\sim 286.2 \mathrm{eV}$ and $\sim 284.7 \mathrm{eV}$ was contributed to the $\mathrm{C}-\mathrm{O}$ groups and $\mathrm{C}-\mathrm{C}$ groups from $\mathrm{pD}$ films on the NP surface. Taken together, the FT-IR spectroscopy and XPS studies indicated

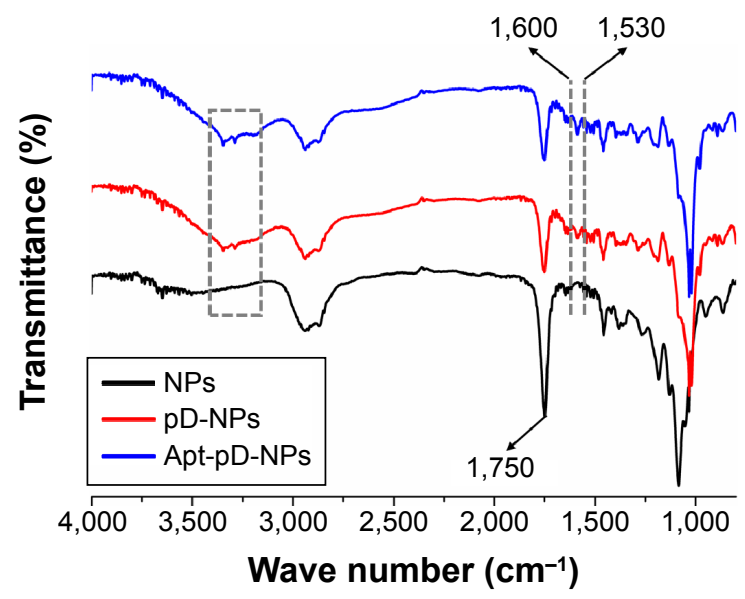

Figure 2 Fourier transform infrared spectra of drug-free NPs, drug-free pD-NPs, and drug-free Apt-pD-NPs.

Notes: The absorption band at $1,750 \mathrm{~cm}^{-1}$ is assigned to the carbonyl band of TPGS and PLGA. The absorption band at $1,600 \mathrm{~cm}^{-1}$ with aromatic rings stretching vibration of $\mathrm{pD}$ supported the fact that the $\mathrm{PD}$ was coated on the surface of NPs. Abbreviations: NPs, nanoparticles; pD, polydopamine; Apt, aptamer; PLGA, poly(lactide-co-glycolide); TPGS, D- $\alpha$-tocopheryl polyethylene glycol 1000 succinate. 

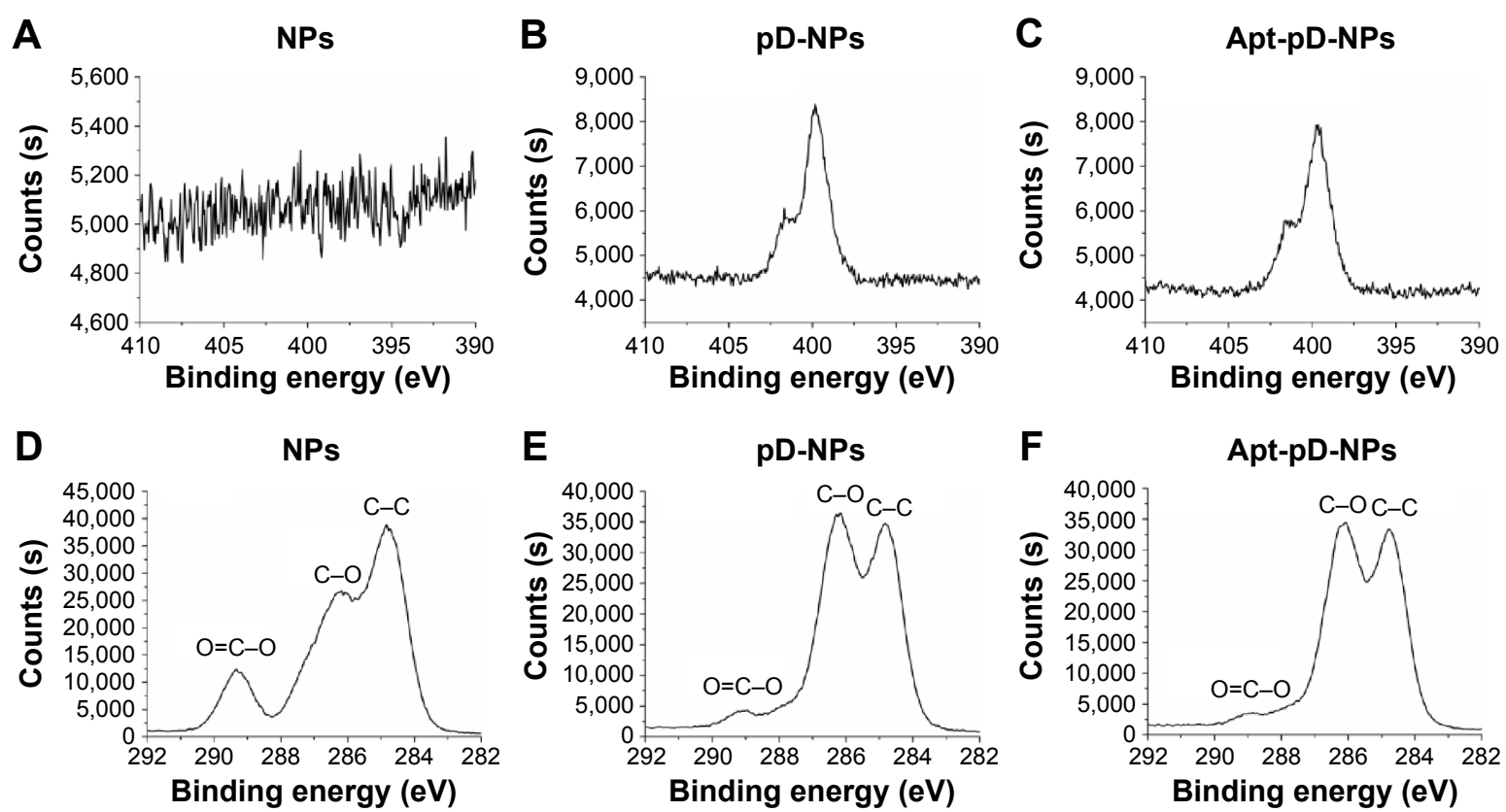

Figure 3 XPS spectra of NPs, pD-NPs, and Apt-pD-NPs.

Notes: (A-C) Narrow scan for $\mathrm{N}$ Is peaks. (D-F) Narrow scan for $\mathrm{C}$ Is peaks. Both pD-NPs and Apt-pD-NPs showed two nitrogen peaks (N Is) at $~ 398.8$ eV (nonprotonated amine groups) and $\sim 402.1 \mathrm{eV}$ (protonated amine groups) in XPS spectra, but bare NPs did not, verifying the presence of pD films on NP surface. Abbreviations: XPS, X-ray photoelectron spectroscopy; NPs, nanoparticles; pD, polydopamine; Apt, aptamer; s, seconds.

the successful incorporation of $\mathrm{pD}$ film and conjugation of AS1411 aptamers on the surface of NPs.

Furthermore, the size and surface properties of NPs have a vital position in drug release, cellular uptake, and in vivo pharmacokinetics. ${ }^{30}$ The FESEM and TEM images of
DTX-loaded NPs, DTX-loaded pD-NPs, and DTX-loaded Apt-pD-NPs are illustrated in Figure 4A-F. Thin spherical films with a single surface could be obviously visualized on the surface of both DTX-loaded pD-NPs and DTX-loaded Apt-pD-NPs, which indicates that $\mathrm{pD}$ films were successfully
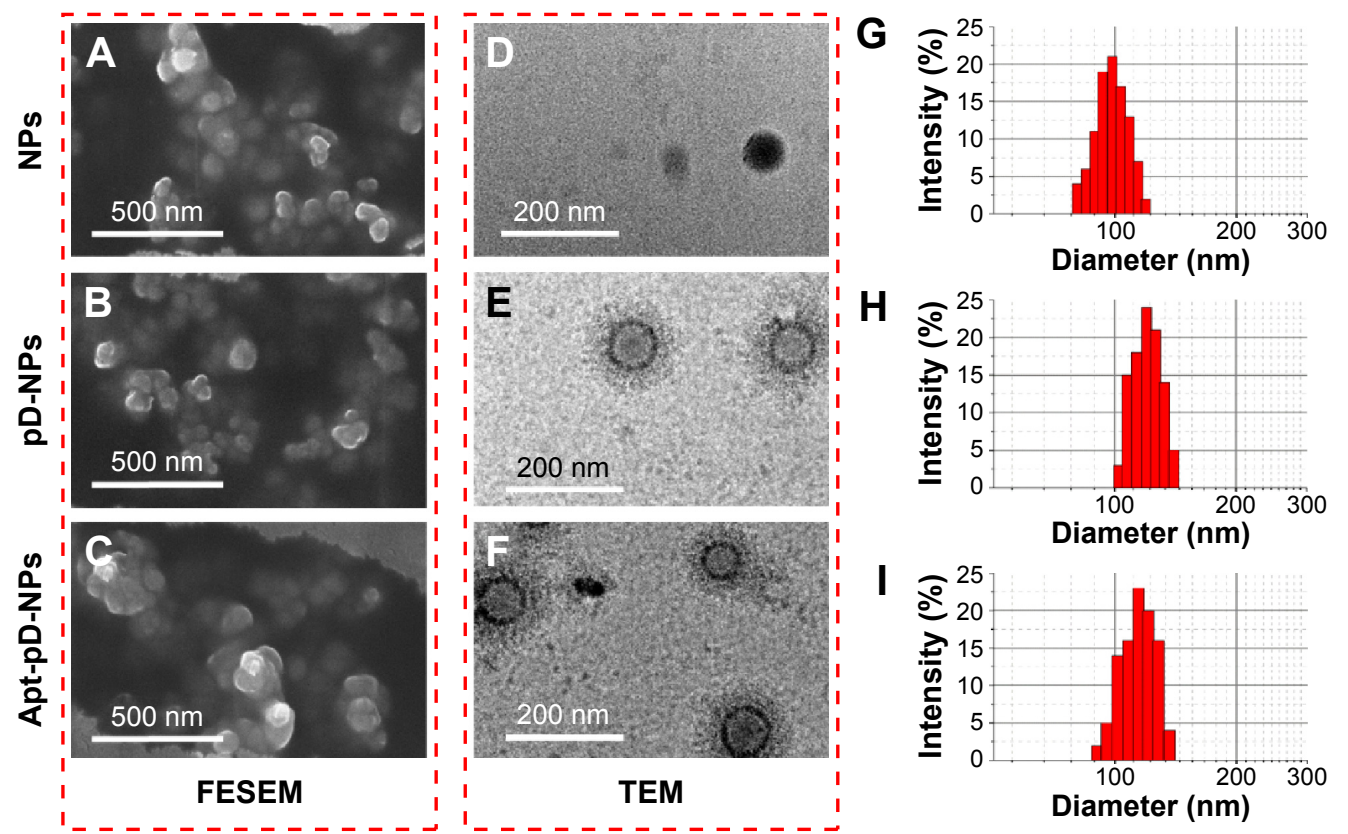

Figure 4 Surface morphology and particle size of DTX-loaded NPs, DTX-loaded pD-NPs, and DTX-loaded Apt-pD-NPs.

Notes: (A-C) FESEM images, (D-F) TEM images, and (G-I) DLS size distribution. Thin spherical films with a single surface could be obviously visualized on the surface of both DTX-loaded pD-NPs and DTX-loaded Apt-pD-NPs, which indicates that pD films were successfully deposited on the surface of NPs. The increased size for DTX-loaded pD-NPs and DTX-loaded Apt-pD-NPs could further confirm the existence of pD film.

Abbreviations: DTX, docetaxel; FESEM, field emission scanning electron microscopy; TEM, transmission electron microscopy; DLS, dynamic light scattering; NPs, nanoparticles; pD, polydopamine; Apt, aptamer. 
Table I Characterization of DTX-loaded NPs, DTX-loaded pDNPs, and DTX-loaded Apt-pD-NPs

\begin{tabular}{llllll}
\hline Samples $(\mathbf{n}=\mathbf{3})$ & Size $(\mathbf{n m})$ & PDI & ZP $(\mathbf{m V})$ & LC $(\%)$ & EE $(\%)$ \\
\hline NPs & $90.8 \pm 4.2$ & 0.163 & $-12.9 \pm 4.3$ & $9.99 \pm 0.47$ & $98.54 \pm 1.63$ \\
pD-NPs & $129.8 \pm 6.7$ & 0.137 & $-14.1 \pm 4.8$ & $9.83 \pm 0.51$ & $98.13 \pm 1.57$ \\
Apt-pD-NPs & $130.1 \pm 2.9$ & 0.168 & $-14.9 \pm 5.1$ & $9.47 \pm 0.42$ & $98.06 \pm 1.46$
\end{tabular}

Note: Data presented as mean \pm standard deviation.

Abbreviations: DTX, docetaxel; NPs, nanoparticles; pD, polydopamine; Apt, aptamer; PDI, polydispersity index; ZP, zeta potential; LC, loading content; EE, encapsulation efficiency.

deposited on the surface of NPs via an oxidative polymerization reaction. The attenuated average particle size (Table 1), which may be induced by a tendency to shrink and collapse while the NPs are in the dry state, ${ }^{24}$ was $\sim 80 \mathrm{~nm}$ in TEM images for DTX-loaded NPs and $\sim 120 \mathrm{~nm}$ for DTX-loaded pD-NPs or DTX-loaded Apt-pD-NPs.

As shown in Table 1, the increased size of DTX-loaded pD-NPs or DTX-loaded Apt-pD-NPs, which reached nearly $40 \mathrm{~nm}$, may be attributed to the thin $\mathrm{pD}$ films (ie, $\sim 20 \mathrm{~nm}$, half of the total increased size) formed around the DTX-loaded NPs and demonstrated the successful coating of $\mathrm{pD}$ through the oxidative polymerization reaction. The size distribution of DTX-loaded NPs, DTX-loaded pD-NPs, and DTX-loaded Apt-pD-NPs is illustrated in Figure 4G-I. The mean hydrodynamic size of DTX-loaded NPs was $\sim 125-135 \mathrm{~nm}$ in diameter, which could easily lead to the accumulation of tumor vasculature under the influence of the enhanced permeability and retention effect. ${ }^{31}$ Because of the good redispersion stability of the DTX-loaded pD-NPs shown in Figure 5, the average size of the NPs hardly changed in the 14 days experiment.

Zeta potential is a vital factor for the stability of the NPs in cellular uptake, drug release, in vivo pharmacokinetics, and biodistribution. ${ }^{32}$ As shown in Table 1, the zeta potential

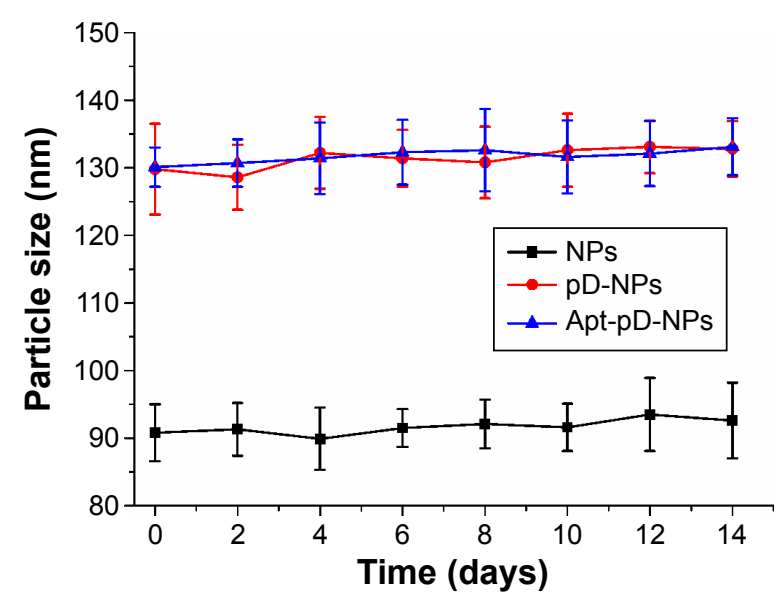

Figure 5 Stability of DTX-loaded NPs, DTX-loaded pD-NPs, and DTX-loaded Apt-pDNPs in PBS, respectively, by monitoring particle size over a span of 2 weeks $(n=3)$. Abbreviations: DTX, docetaxel; NPs, nanoparticles; pD, polydopamine; Apt, aptamer; PBS, phosphate-buffered saline. of the DTX-loaded pD-NPs and DTX-loaded Apt-pD-NPs was observed to be $-14.1 \mathrm{mV}$ and $-14.9 \mathrm{mV}$, respectively, which is slightly higher than that of the DTX-loaded NPs ( $-12.9 \mathrm{mV}$ ), which may be caused by the slightly negative charge of NPs. As can be seen from Table 1, the LC and EE of Apt-pD-DTX/NPs $(9.47 \% \pm 0.42 \%, 98.06 \% \pm 1.46 \%)$ were a little bit lower than DTX/NPs $(9.99 \% \pm 0.47 \%$, $98.54 \% \pm 1.63 \%)$ and $\mathrm{pD}-\mathrm{DTX} / \mathrm{NPs}(9.83 \% \pm 0.51 \%$, $98.13 \% \pm 1.57 \%$ ), which may be caused by the loss of a few loaded drugs when aptamers were conjugated to the NPs.

\section{In vitro drug release kinetics}

In vitro DTX release from DTX-loaded NPs, DTX-loaded pD-NPs, or DTX-loaded Apt-pD-NPs was surveyed in the release medium ( $\mathrm{pH} 7.4$, PBS containing $0.1 \% \mathrm{w} / \mathrm{v}$ Tween 80 ) at $37^{\circ} \mathrm{C}$ (Figure 6). A fast release of DTX-loaded NPs, DTXloaded pD-NPs, or DTX-loaded Apt-pD-NPs was exhibited in the initial 48 hours, that is, $\sim 45 \%$ of the encapsulated drugs were released in all NPs. After 14 days, 72.57\%, 70.48\%, and $69.87 \%$ of drugs were released from DTX-loaded NPs, DTX-loaded pD-NPs, and DTX-loaded Apt-pD-NPs, respectively. The release rate from DTX-loaded NPs, DTX-loaded pD-NPs, and DTX-loaded Apt-pD-NPs was quite similar, indicating that the $\mathrm{pD}$-coating and AS1411 conjugation did not have much influence on the drug release properties of the DTX-loaded NPs. Thus, the DTX-loaded Apt-pD-NPs can be a promising drug delivery vector in nanomedicine research.

\section{Cellular uptake of fluorescent NPs and in vitro cellular targeting}

The cellular uptake profile of the NPs was investigated because of the important roles that the cellular internalization

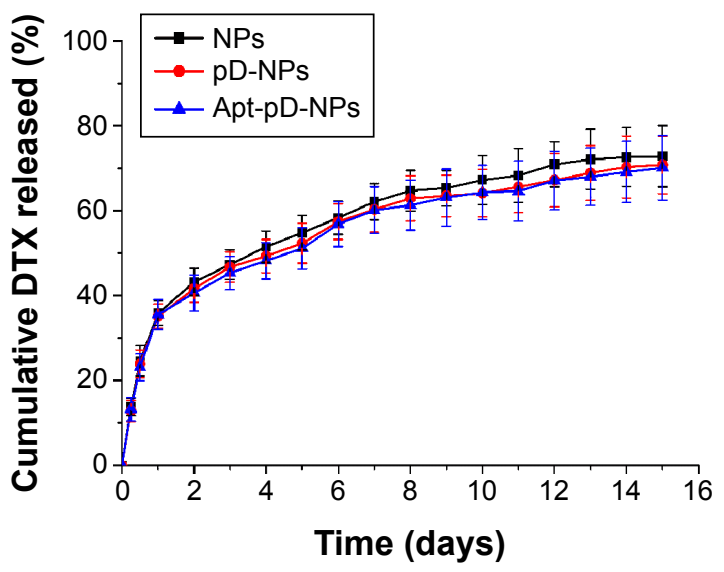

Figure 6 In vitro drug release profile of DTX-loaded NPs, DTX-loaded pD-NPs, and DTX-loaded Apt-pD-NPs.

Notes: The PD-coating and ASI4I I conjugation seemed to not have much influence on the drug release properties of the DTX-loaded NPs.

Abbreviations: DTX, docetaxel; NPs, nanoparticles; pD, polydopamine; Apt, aptamer 
and sustained retention play on the therapeutic effects of the NPs. ${ }^{33}$ Figure $7 \mathrm{~A}$ shows the confocal laser scanning microscope images of the HeLa cells after 2-hours incubation with the suspension of $250 \mu \mathrm{g} / \mathrm{mL}$ C6-loaded NPs in DMEM. As shown in the figure, the fluorescence intensity, which represents the cellular uptake efficiency, was nearly equivalent between the cells incubated with C6-loaded NPs and C6-loaded pD-NPs. Furthermore, the existence of aptamers on the surface of NPs may lead to high-efficiency in vitro cellular targeting, and the fluorescence intensity increased significantly after 2 hours incubation with the C6-loaded Apt-pD-NPs. To verify the significant role of aptamers in the cellular uptake of the C6-loaded Apt-pDNPs, we performed a receptor competition assay by selecting aptamers as the competitive reagent. When the C6-loaded Apt-pD-NPs and aptamers were added to wells at the same time, the fluorescence was significantly quenched. Furthermore, with LNCaP cells (AS1411 nonspecific cancer cells) used as control, the fluorescence observed in LNCaP cells was also significantly decreased compared with HeLa cells incubated with the C6-loaded Apt-pD-NPs. These tests certified the tumor targeting specificity of the C6-loaded Apt-pD-NPs.

As displayed in Figure 7B, HeLa cells were incubated with the C6-loaded NPs, the C6-loaded pD-NPs, or the C6-loaded Apt-pD-NPs for 2 hours at the concentration of $100 \mu \mathrm{g} / \mathrm{mL}, 250 \mu \mathrm{g} / \mathrm{mL}$, and $500 \mu \mathrm{g} / \mathrm{mL}$, respectively, to quantitatively investigate the cellular uptake efficacy. The cellular uptake efficiency of C6-loaded NPs, which was similar to the C6-loaded pD-NPs at all NPs concentration, was only $87.83 \%, 78.19 \%$, and $72.12 \%$ of the C6-loaded Apt-pD-NPs at the concentration of $100 \mu \mathrm{g} / \mathrm{mL}, 250 \mu \mathrm{g} / \mathrm{mL}$, and $500 \mu \mathrm{g} / \mathrm{mL}$, respectively. Therefore, we consider that the high uptake efficiency can be attributed to the targeting ligands (ie, AS1411 aptamers) on the surface of the NPs. The specific interactions caused by AS1411 aptamers reinforce that the endocytosis of NPs was resulted in the fluorescence intensity of cells treated with the C6-loaded Apt-pD-NPs. The endocytosis of the C6-loaded NPs, the C6-loaded pD-NPs, and the C6-loaded Apt-pD-NPs was
A

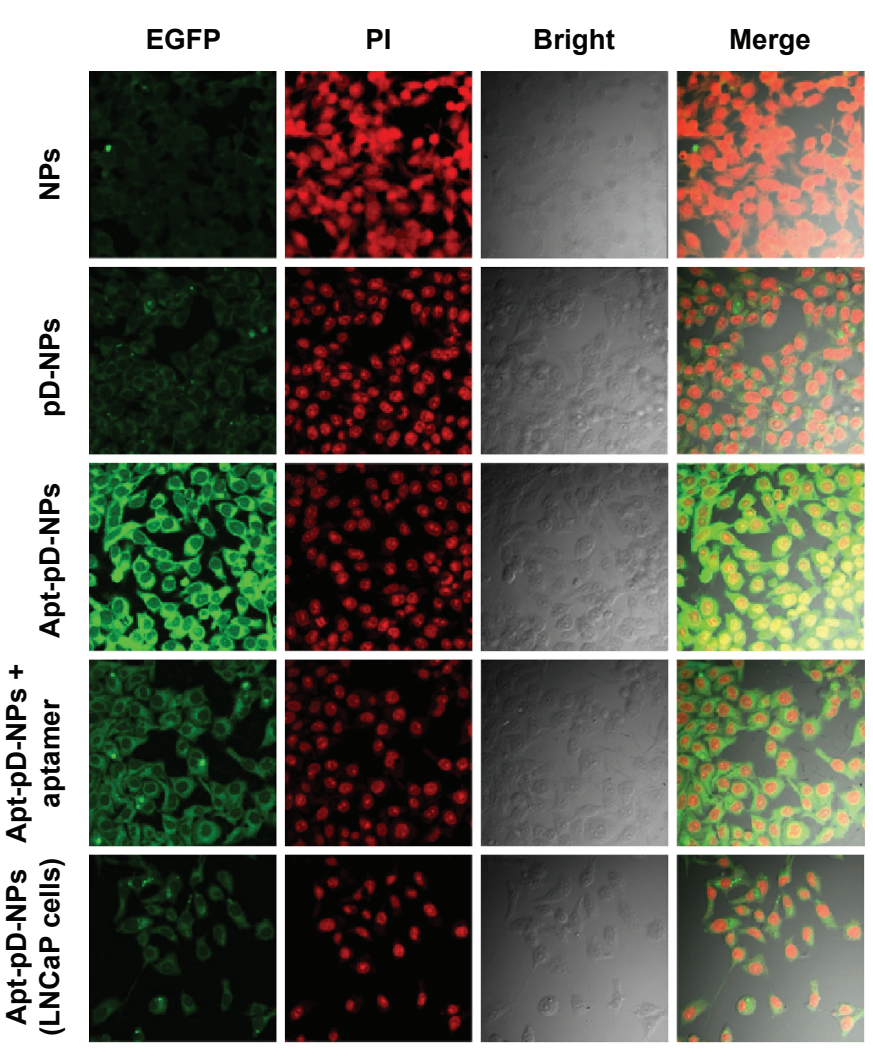

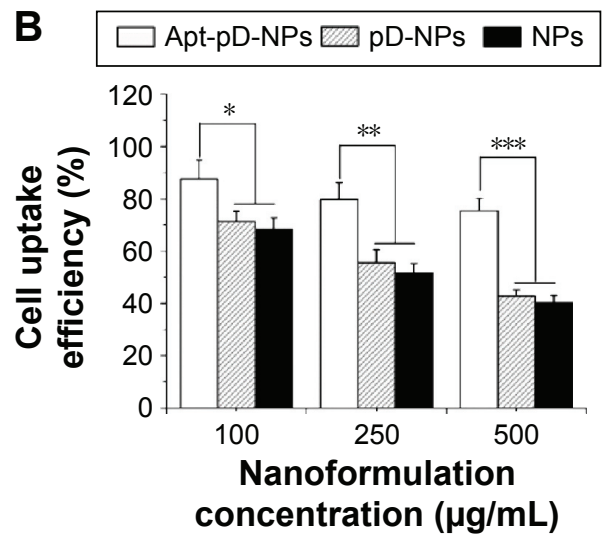

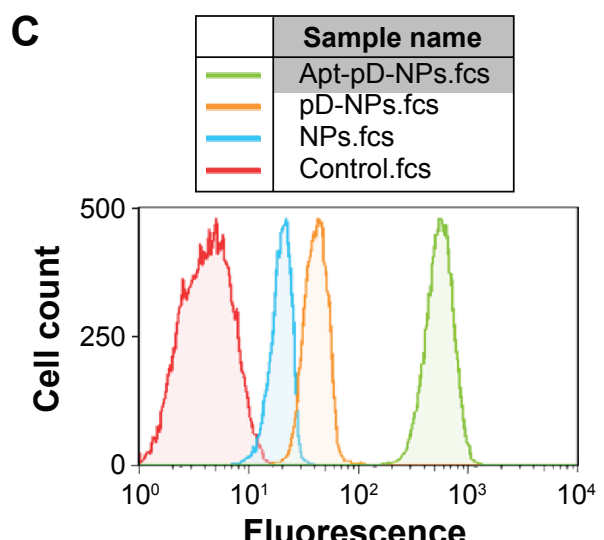

Figure 7 Endocytosis of C6-loaded NPs, C6-loaded pD-NPs, and C6-loaded Apt-pD-NPs.

Notes: (A) CLSM images of HeLa and LNCaP cells after 2 hours incubation at $37^{\circ} \mathrm{C}$. (B) Cellular uptake efficiency of all kinds of NPs in HeLa cells after 2 hours incubation at $37^{\circ} \mathrm{C}$ (Student's $t$-test, $* P<0.05, * * P<0.01$, $* * * P<0.001$ ). (C) FCM histograms for all kinds of NPs in HeLa cells after I hour incubation at $37^{\circ} \mathrm{C}$.

Abbreviations: C6, coumarin-6; NPs, nanoparticles; PD, polydopamine; Apt, aptamer; CLSM, confocal laser scanning microscope; FCM, flow cytometry method; EGFP, enhanced green fluorescent protein; PI, propidium iodide. 
further confirmed by flow cytometry method assay with similar results shown in Figure 7C.

\section{Effects of NPs on cell viability}

MTT assay was used to evaluate the cytotoxicity (in vitro cell viability) of DTX-loaded NPs, DTX-loaded pD-NPs, and DTX-loaded Apt-pD-NPs. Taxotere, a kind of DTX formulation that is clinically available, was chosen as the reference.
After excluding any contamination, HeLa cells were treated at the concentration of $0.25 \mu \mathrm{g} / \mathrm{mL}, 2.5 \mu \mathrm{g} / \mathrm{mL}, 12.5 \mu \mathrm{g} / \mathrm{mL}$, and $25 \mu \mathrm{g} / \mathrm{mL}$ equivalent DTX concentrations for 24 hours, 48 hours, and 72 hours, respectively. We can conclude from Figure 8 that 1 ) the cellular viability decreased with the increase of incubation time for both Taxotere and nanoformulations, exhibiting a dose-dependent and time-dependent effect, especially for the DTX-loaded Apt-pD-NPs;

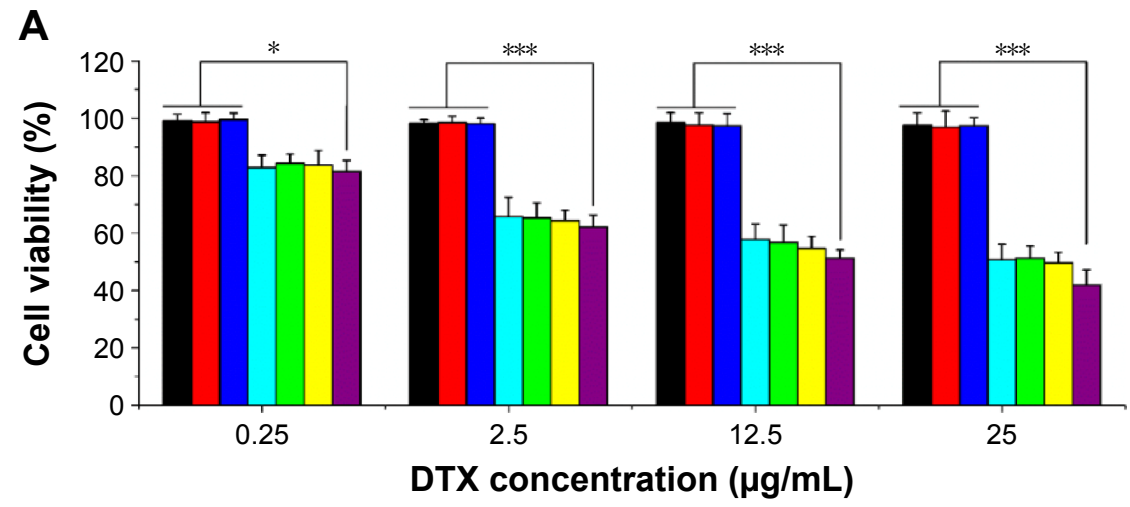

B
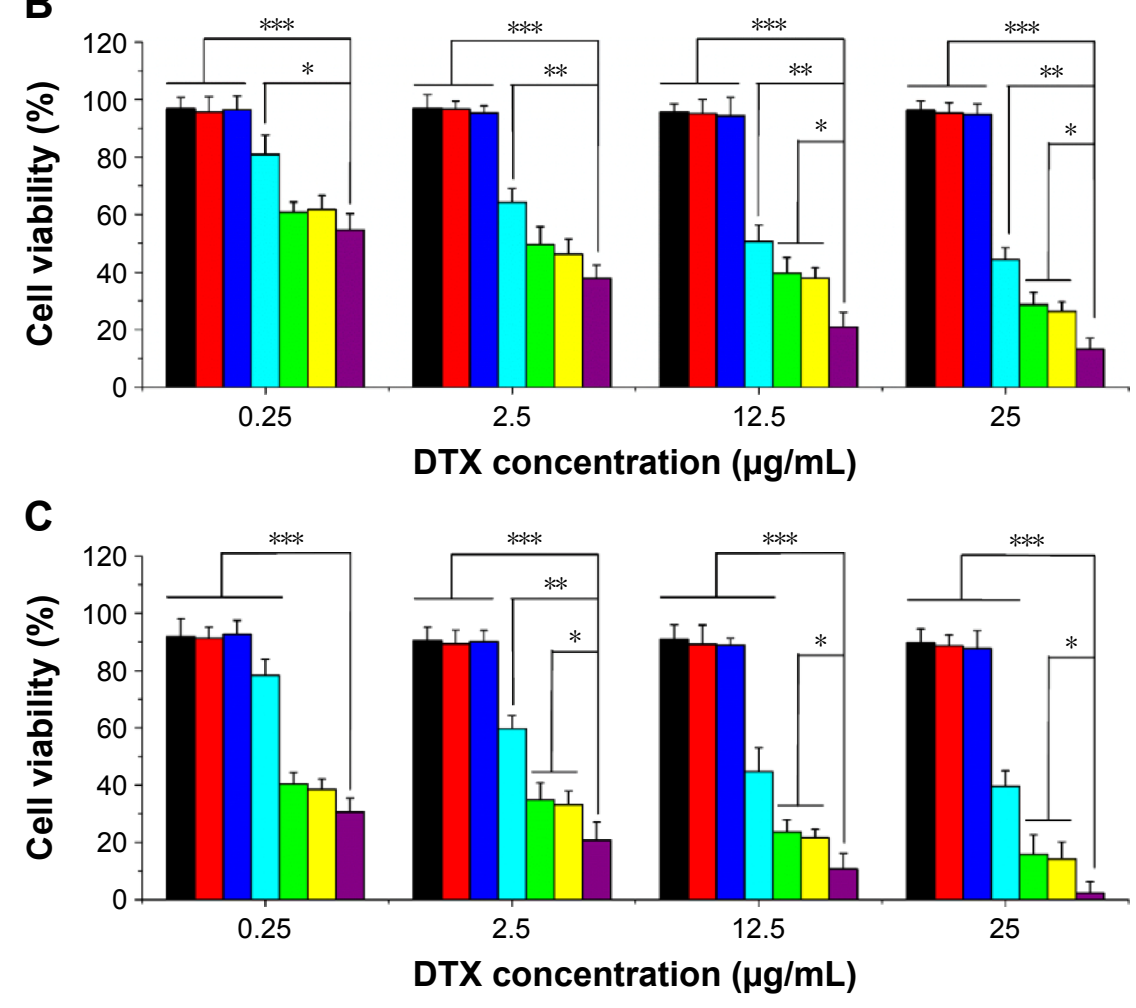

Drug-free NPs $\square$ Drug-free pD-NPs $\square$ Drug-free Apt-pD-NPs $\square$ Taxotere
DTX-loaded NPs $\square$ DTX-loaded pD-NPs $\square$ DTX-loaded Apt-pD-NPs

Figure 8 Cytotoxicity of all kinds of NPs detected by MTT assays $(n=5)$.

Notes: Viability of HeLa cells cultured with DTX-loaded Apt-pD-NPs in comparison with that of Taxotere ${ }^{\circledR}$ at the same DTX dose and that of DTX-loaded NPs and pD-NPs with the same amount of NPs for (A) 24 hours, (B) 48 hours, and (C) 72 hours (Student's $t$-test, $* P<0.05$, $* * P<0.01$, $* * * P<0.00$ I). Drug-free NPs, pD-NPs, and Apt-pD-NPs were taken as control.

Abbreviations: NPs, nanoparticles; MTT, 3-(4,5-dimethylthiazol-2-yl)-2,5-diphenyltetrazolium bromide; DTX, docetaxel; Apt, aptamer; pD, polydopamine. 
2) none of the drug-free NPs exhibited obvious cytotoxicity to $\mathrm{HeLa}$ cells at various concentrations from $0.25 \mu \mathrm{g} / \mathrm{mL}$ to $25 \mu \mathrm{g} / \mathrm{mL}$, illustrating that both the copolymer and the modification of NPs (pD coating and conjugation of aptamers) were biocompatible and nontoxic to cells and tissues; 3) the DTX-loaded Apt-pD-NPs exhibited better in vitro antitumor efficacy than Taxotere, the DTX-loaded NPs, and the DTX-loaded pD-NPs on HeLa cells. For example, the HeLa cellular viability ( 72 hours, $12.5 \mu \mathrm{g} / \mathrm{mL}$ ) was $41.93 \%$ for Taxotere, $21.62 \%$ for the DTX-loaded NPs, $19.26 \%$ for the DTX-loaded pD-NPs, and $11.61 \%$ for the DTX-loaded Apt-pD-NPs. 4) The DTX-loaded NPs and the DTX-loaded pD-NPs showed similar cytotoxicity at various concentrations from $0.25 \mu \mathrm{g} / \mathrm{mL}$ to $25 \mu \mathrm{g} / \mathrm{mL}$, further indicating that the $\mathrm{pD}$ film on the surface of the NPs did not influence the cell viability, being biocompatible and nontoxicity.

In comparison with clinically available Taxotere, the DTX-loaded NPs, and the DTX-loaded pD-NPs, the cytotoxicity of HeLa cells after 72 hours of incubation with the DTX-loaded Apt-pD-NPs was 36.79\%, 10.78\%, and 6.75\% larger at the DTX concentration of $25 \mu \mathrm{g} / \mathrm{mL}$, indicating that the aptamers may have an outstanding targeting effect on the NP surface. Hence, targeted DTX-loaded Apt-pD-NPs could be used as a promising drug delivery system with their extremely high-efficiency in vitro therapeutic effects and in vivo treatment.

$\mathrm{IC}_{50}$ value, which is defined as the drug inhibitory concentration causing 50\% tumor cell mortality in a designated period, could be used to quantitatively evaluate the in vitro therapeutic effects of a pharmaceutical formulation. ${ }^{34}$ Table 2 shows the $\mathrm{IC}_{50}$ values of HeLa cells after 24 hours, 48 hours, and 72 hours incubation with clinically available Taxotere, the DTX-loaded NPs, the DTX-loaded pD-NPs, and the DTX-loaded Apt-pD-NPs (calculated from Figure 8). As revealed in Table 2, the $\mathrm{IC}_{50}$ values of the DTX-loaded NPs and the DTX-loaded pD-NPs for HeLa cells were

Table 2 IC $_{50}$ values of Taxotere ${ }^{\circledR}$, DTX-loaded NPs, DTX-loaded pD-NPs and DTX-loaded Apt-pD-NPs on HeLa cells after $24 \mathrm{~h}$, $48 \mathrm{~h}$, and $72 \mathrm{~h}$ incubation

\begin{tabular}{lllll}
\hline $\begin{array}{l}\text { Incubation } \\
\text { time (h) }\end{array}$ & \multicolumn{1}{l}{$\mathrm{IC}_{50}(\mu \mathrm{g} / \mathrm{mL})$} & & & \\
\cline { 2 - 5 } & Taxotere & NPs & pD-NPs & Apt-pD-NPs \\
\hline 24 & $19.86 \pm \mathrm{I} .62$ & $19.89 \pm \mathrm{I} .5 \mathrm{I}$ & $19.87 \pm \mathrm{I} .64$ & $\mathrm{I} 4.3 \mathrm{I} \pm \mathrm{I} .27$ \\
48 & $12.03 \pm 0.89$ & $3.0 \mathrm{I} \pm 0.63$ & $3.07 \pm 0.59$ & $0.47 \pm 0.09$ \\
72 & $7.84 \pm 0.76$ & $0.007 \pm 0.002$ & $0.006 \pm 0.004$ & $0.0003 \pm 0.000 \mathrm{I}$ \\
\hline
\end{tabular}

Notes: $I C_{5}$, the drug concentration at which the growth of $50 \%$ cells was inhibited. Data presented as mean \pm standard deviation.

Abbreviations: DTX, docetaxel; NPs, nanoparticles; pD, polydopamine; Apt, aptamer; $h$, hours.
$19.89 \mu \mathrm{g} / \mathrm{mL}$ and $19.87 \mu \mathrm{g} / \mathrm{mL}$ after 24 hours incubation, respectively, $3.01 \mu \mathrm{g} / \mathrm{mL}$ and $3.07 \mu \mathrm{g} / \mathrm{mL}$ after 48 hours incubation, respectively, and $0.007 \mu \mathrm{g} / \mathrm{mL}$ and $0.006 \mu \mathrm{g} / \mathrm{mL}$ after 72 hours incubation, respectively, which was also consistent with the results obtained from cellular uptake experiments and indicated no obvious effect would be brought after $\mathrm{pD}$ coating. In the meantime, the $\mathrm{IC}_{50}$ value of the DTX-loaded Apt-pD-NPs for HeLa cells was $14.31 \mu \mathrm{g} / \mathrm{mL}$, only a little smaller than Taxotere $(19.86 \mu \mathrm{g} / \mathrm{mL})$ after 24 hours incubation. However, that of DTX-loaded Apt-pD-NPs was 25.60 -fold smaller than that of Taxotere $(0.47 \mu \mathrm{g} / \mathrm{mL}$ vs $12.03 \mu \mathrm{g} / \mathrm{mL}$ ) after 48 hours incubation. The advantages in tumor inhibition of clinical Taxotere $<$ the DTX-loaded NPs (or the DTX-loaded pD-NPs) $<$ the DTX-loaded AptpD-NPs could be concluded, demonstrating significant in vitro therapeutic effects and great possibilities for in vivo treatment of the targeted DTX-loaded Apt-pD-NPs.

\section{In vivo antitumor effects of NPs}

On the basis of the earlier experiments in vitro cytotoxicity against HeLa cells, the DTX-loaded Apt-pD-NPs could be used as a promising drug delivery vector in cancer therapeutic research. Compared with saline (control group), both clinically available Taxotere and therapeutic NPs inhibited the tumor growth (shown in Figure 9A). The DTX-loaded Apt-pD-NPs had a better effect than the nontargeted DTXloaded $\mathrm{pD}-\mathrm{NPs}$ and clinical Taxotere, and these results (Figure 9A and 9B) were consistent with previous cellular uptake and cytotoxicity results. The tumor status of health and the morphology of tumors in each group on day 24 are shown in Figure 9C, and the tumor site was indicated by a dotted cycle. As shown in the figure, the size of the tumors could be directly observed and a similar conclusion could be achieved through this figure. Furthermore, only the mice treated in Taxotere group seemed to be emaciated with the protrusion of the vertebral column. No physical deterioration or unhealthy status was found in therapeutic NPs groups, indicating that less side effects would be caused by the therapeutic NPs. The survival data were studied using another batch of nude mice, and were presented as Kaplan-Meier plots and analyzed with a log-rank test. Compared with nontargeted DTX-loaded pD-NPs, DTX-loaded NPs, Taxotere, and saline, the survival time of targeted DTX-loaded Apt-pD-NPs was increased by 11 days, 10 days, 15 days, and 20 days, and the lifetime was extended by $24.44 \%, 21.74 \%$, $36.59 \%$, and $55.56 \%$, respectively, as shown in Figure 9B, which turned out that targeted DTX-loaded Apt-pD-NPs worked significantly better than clinically used Taxotere 

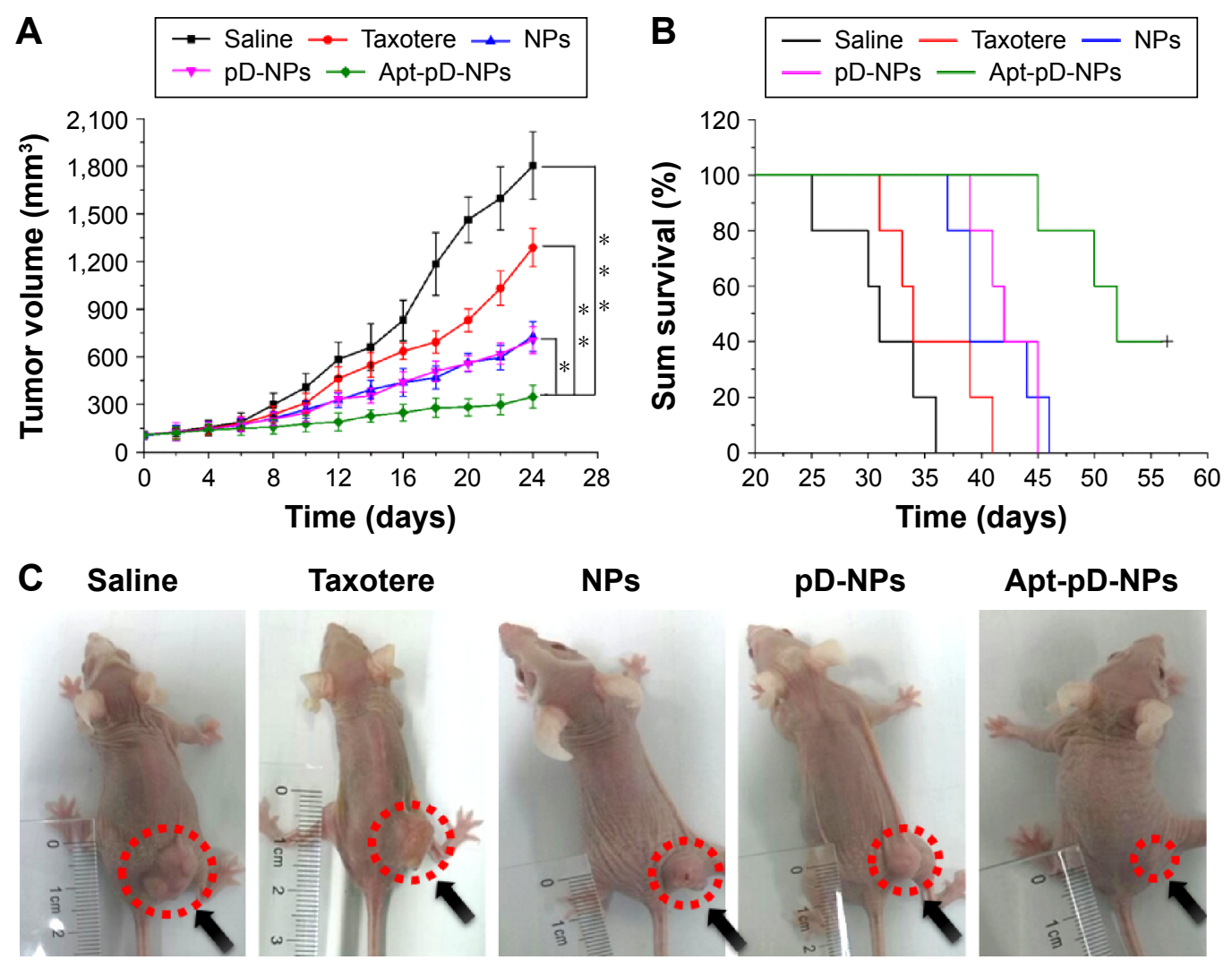

Figure 9 Antitumor efficacy of Taxotere ${ }^{\circledR}$, DTX-loaded pD-NPs, and DTX-loaded Apt-pD-NPs on the SCID nude mice bearing HeLa xenograft ( $\left.n=5\right)$.

Notes: (A) Tumor growth curve after intravenous injection with saline, Taxotere, DTX-loaded pD-NPs, and DTX-loaded Apt-pD-NPs (Student's $t$-test, $* P<0.05$, ** $P<0.0$, $* * * P<0.001)$. (B) Kaplan-Meier survival log-rank analysis of the SCID nude mice bearing HeLa xenograft. The survival time of the animals that received DTX-loaded Apt-pD-NPs was significantly longer than that of those that received DTX-loaded NPs, DTX-loaded pD-NPs, Taxotere, and saline. (C) The status of health and the morphology of tumors in each group on day 24. The tumor site is indicated by a dotted circle.

Abbreviations: DTX, docetaxel; pD, polydopamine; NPs, nanoparticles; Apt, aptamer; SCID, severe combined immunodeficient.

and nontargeted DTX-loaded pD-NPs and DTX-loaded NPs, suggesting that DTX-loaded Apt-pD-NPs could be used as a promising and high-efficiency drug delivery system for cervical cancer therapy. In addition, the in vivo antitumor effect of DTX-loaded Apt-pD-NPs reported here was better than our previous studies using DTX-loaded M-PLGA-TPGS NPs, ${ }^{24}$ DTX-loaded CA-(PCL-ran-PLA)- $b-\mathrm{PEG}_{1 \mathrm{k}} \mathrm{NPs},{ }^{35}$ or DTXloaded $\mathrm{H}_{40}-\mathrm{PLA}-b-\mathrm{TPGS}^{36}$ in tumor xenograft model.

\section{Conclusion}

In this work, we have successfully synthesized a kind of novel and robust DTX-loaded Apt-pD-NPs with star-shaped M-PLGA-TPGS copolymers for the first time, which was used as a promising and high-efficiency drug carrier for cervical cancer therapy. The M-PLGA-TPGS NPs were simply functionalized by aptamers based on the facile dopamine polymerization method. The DTX-loaded Apt-pD-NPs were characterized by DLS size and zeta potential, FT-IR, XPS, TEM, SEM, and in vitro drug release profile successfully. Through the endocytosis of fluorescent NPs and in vitro cellular targeting assay, it was demonstrated that the C6-loaded Apt-pD-NPs can specifically target to HeLa cells compared with C6-loaded NPs and C6-loaded pD-NPs. The in vitro cytotoxicity assay showed that the DTX-loaded Apt-pD-NPs significantly inhibit cell proliferation in comparison with DTX-loaded NPs and DTX-loaded pD-NPs. The in vivo antitumor assays showed enhanced therapeutic effects of the DTX-loaded Apt-pD-NPs as well as the improved survival rate and reduced side effects. All data obtained from the in vivo assays were consistent with the in vitro experiments, suggesting that the robust DTX-loaded Apt-pD-NPs could be used as potential nanotherapeutics for cervical cancer treatment and the aptamer-polydopamine modification strategy could be a promising method for active targeting of cancer therapy with simple procedures.

\section{Acknowledgments}

This work was supported by the Natural Science Foundation of Guangdong Province for PhD Startup (Novel Docetaxel/ SiPHB1 Long-Circulating Codelivery Nanosystem for 
Enhanced Therapeutic Effects of Liver cancer; Sequence No 2016A030310023), Tsinghua Scholarship for Overseas Graduate Studies (No 2013159), National Natural Science Foundation of China (Nos 31270019 and 51203085), Program for New Century Excellent Talents in University (NCET-11-0275), Guangdong Natural Science Funds for Distinguished Young Scholar (No 2014A030306036), Scientific and Technological Innovation Bureau of Anshan District (No KC2014JSCX0023A), and Science, Technology \& Innovation Commission of Shenzhen Municipality (No CYZZ 20130320110255352).

\section{Disclosure}

The authors report no conflicts of interest in this work.

\section{References}

1. Zeng X, Tao W, Mei L, Huang L, Tan C, Feng SS. Cholic acidfunctionalized nanoparticles of star-shaped PLGA-vitamin E TPGS copolymer for docetaxel delivery to cervical cancer. Biomaterials. 2013; 34(25):6058-6067.

2. Lv L, Guo Y, Shen Y, et al. Intracellularly degradable, self-assembled amphiphilic block copolycurcumin nanoparticles for efficient in vivo cancer chemotherapy. Adv Healthc Mater. 2015;4(10):1496-1501.

3. Cui M, Naczynski DJ, Zevon M, et al. Multifunctional albumin nanoparticles as combination drug carriers for intra-tumoral chemotherapy. Adv Healthc Mater. 2013;2(9):1236-1245.

4. Duncan R. The dawning era of polymer therapeutics. Nat Rev Drug Discov. 2003;2(5):347-360.

5. Liao JF, Wang C, Wang YJ, Luo F, QianZY. Recent advances in formation, properties, and applications of polymersomes. Curr Pharm Des. 2012; 18(23):3432-3441.

6. Liu YY, Miyoshi H, Nakamura M. Nanomedicine for drug delivery and imaging: a promising avenue for cancer therapy and diagnosis using targeted functional nanoparticles. Int J Cancer. 2007;120(12): 2527-2537.

7. Mahapatro A, Singh DK. Biodegradable nanoparticles are excellent vehicle for site directed in-vivo delivery of drugs and vaccines. J Nanobiotechnology. 2011;9:55.

8. Vert M. Degradable and bioresorbable polymers in surgery and in pharmacology: beliefs and facts. J Mater Sci Mater Med. 2009;20(2): $437-446$.

9. Tao W, Zhang J, Zeng X, et al. Blended nanoparticle system based on miscible structurally similar polymers: a safe, simple, targeted, and surprisingly high efficiency vehicle for cancer therapy. Adv Healthc Mater. 2015;4(8):1203-1214.

10. Dhar S, Gu FX, Langer R, Farokhzad OC, Lippard SJ. Targeted delivery of cisplatin to prostate cancer cells by aptamer functionalized Pt(IV) prodrug-PLGA-PEG nanoparticles. Proc Natl Acad Sci U S A. 2008; 105(45):17356-17361.

11. Farokhzad OC, Jon S, Khademhosseini A, Tran TN, Lavan DA, Langer R. Nanoparticle-aptamer bioconjugates: a new approach for targeting prostate cancer cells. Cancer Res. 2004;64(21):7668-7672.

12. Guo JW, Gao XL, Su LN, et al. Aptamer-functionalized PEG-PLGA nanoparticles for enhanced anti-glioma drug delivery. Biomaterials. 2011; 32(31):8010-8020.

13. Jiang F, Kumar RA, Jones RA, Patel DJ. Structural basis of RNA folding and recognition in an AMP-RNA aptamer complex. Nature. 1996; 382(6587): $183-186$

14. Kim MG, Shon Y, Lee J, et al. Double stranded aptamer-anchored reduced graphene oxide as target-specific nano detector. Biomaterials. 2014; 35(9):2999-3004.
15. Li LL, Yin Q, Cheng JJ, Lu Y. Polyvalent mesoporous silica nanoparticle-aptamer bioconjugates target breast cancer cells. $A d v$ Healthc Mater. 2012;1(5):567-572.

16. Ho HA, Leclerc M. Optical sensors based on hybrid aptamer/conjugated polymer complexes. J Am Chem Soc. 2004;126(5):1384-1387.

17. Wei Q, Zhang F, Li J, Li B, Zhao C. Oxidant-induced dopamine polymerization for multifunctional coatings. Polym Chem. 2010;1(9):1430.

18. Zhu D, Tao W, Zhang H, et al. Docetaxel (DTX)-loaded polydopaminemodified TPGS-PLA nanoparticles as a targeted drug delivery system for the treatment of liver cancer. Acta Biomater. 2016;30:144-154.

19. Park J, Brust TF, Lee HJ, Lee SC, Watts VJ, Yeo Y. Polydopaminebased simple and versatile surface modification of polymeric nano drug carriers. ACS Nano. 2014;8(4):3347-3356.

20. Jiang JH, Zhu LP, Zhu LJ, Zhu BK, Xu YY. Surface characteristics of a self-polymerized dopamine coating deposited on hydrophobic polymer films. Langmuir. 2011;27(23):14180-14187.

21. Lee H, Dellatore SM, Miller WM, Messersmith PB. Mussel-inspired surface chemistry for multifunctional coatings. Science. 2007;318(5849): 426-430.

22. Lee H, Rho J, Messersmith PB. Facile conjugation of biomolecules onto surfaces via mussel adhesive protein inspired coatings. Adv Mater. 2009; 21(4):431-434.

23. Tao W, Zeng X, Wu J, et al. Polydopamine-based surface modification of novel nanoparticle-aptamer bioconjugates for in vivo breast cancer targeting and enhanced therapeutic effects. Theranostics. 2016; 6(4):470-484.

24. Tao W, Zeng XW, Liu T, et al. Docetaxel-loaded nanoparticles based on star-shaped mannitol-core PLGA-TPGS diblock copolymer for breast cancer therapy. Acta Biomater. 2013;9(11):8910-8920.

25. Valencia PM, Hanewich-Hollatz MH, Gao W, et al. Effects of ligands with different water solubilities on self-assembly and properties of targeted nanoparticles. Biomaterials. 2011;32(26):6226-6233.

26. Ma Y, Zheng Y, Zeng X, et al. Novel docetaxel-loaded nanoparticles based on PCL-Tween 80 copolymer for cancer treatment. Int $J$ Nanomedicine. 2011;6:2679-2688.

27. Yu Q, Cao J, Chen B, et al. Efficient gene delivery to human umbilical cord mesenchymal stem cells by cationized Porphyra yezoensis polysaccharide nanoparticles. Int J Nanomedicine. 2015;10:7097-7107.

28. Bernabeu E, Helguera G, Legaspi MJ, et al. Paclitaxel-loaded PCL-TPGS nanoparticles: in vitro and in vivo performance compared with Abraxane (R). Colloid Surf B. 2014;113:43-50.

29. Zhang M, Zhang XH, He XW, Chen LX, Zhang YK. A self-assembled polydopamine film on the surface of magnetic nanoparticles for specific capture of protein. Nanoscale. 2012;4(10):3141-3147.

30. Perrault SD, Walkey C, Jennings T, Fischer HC, Chan WCW. Mediating tumor targeting efficiency of nanoparticles through design. Nano Lett. 2009;9(5):1909-1915.

31. Yan F, Zhang C, Zheng Y, et al. The effect of poloxamer 188 on nanoparticle morphology, size, cancer cell uptake, and cytotoxicity. Nanomedicine. 2010;6(1):170-178.

32. Sanna V, Roggio AM, Siliani S, et al. Development of novel cationic chitosan-and anionic alginate-coated poly(d,l-lactide-co-glycolide) nanoparticles for controlled release and light protection of resveratrol. Int J Nanomedicine. 2012;7:5501-5516.

33. Xu A, Yao M, Xu G, et al. A physical model for the size-dependent cellular uptake of nanoparticles modified with cationic surfactants. Int J Nanomedicine. 2012;7:3547-3554.

34. Xie J, Shen Z, Li KCP, Danthi N. Tumor angiogenic endothelial cell targeting by a novel integrin-targeted nanoparticle. Int J Nanomedicine. 2007; 2(3):479-485

35. Tao W, Zeng XW, Zhang JX, et al. Synthesis of cholic acid-core poly(epsilon-caprolactone-ran-lactide)-b-poly(ethylene glycol) 1,000 random copolymer as a chemotherapeutic nanocarrier for liver cancer treatment. Biomater Sci. 2014;2(9):1262-1274.

36. Zeng XW, Tao W, Wang ZY, et al. Docetaxel-loaded nanoparticles of dendritic amphiphilic block copolymer H40-PLA-b-TPGS for cancer treatment. Part Part Syst Char. 2015;32(1):112-122. 
International Journal of Nanomedicine

Dovepress

\section{Publish your work in this journal}

The International Journal of Nanomedicine is an international, peerreviewed journal focusing on the application of nanotechnology in diagnostics, therapeutics, and drug delivery systems throughout the biomedical field. This journal is indexed on PubMed Central, MedLine, CAS, SciSearch ${ }^{\circledR}$, Current Contents ${ }^{\circledR} /$ Clinical Medicine,
Journal Citation Reports/Science Edition, EMBase, Scopus and the Elsevier Bibliographic databases. The manuscript management system is completely online and includes a very quick and fair peer-review system, which is all easy to use. Visit http://www.dovepress.com/ testimonials.php to read real quotes from published authors.

Submit your manuscript here: http://www.dovepress.com/international-journal-of-nanomedicine-journal 